\title{
"A ÚLTIMA AVENTURA" DE ROMY POCZTARUK: UMA VIAGEM ENTRE AS UTOPIAS E RUÍNAS NA REGIÃO AMAZÔNICA
}

\section{Romy Pocztaruk's "Last Adventure": a journey between utopias and ruins in the amazon region}

La "Última Aventura" de Romy Pocztaruk: un viaje entre utopías y ruinas en la región amazónica

$>$ Rafael Fontes Gaspar [Universidade Estadual de Santa Catarina, Brasil]*

Citação recomen-
dada: GASPAR,
Rafael Fontes. "A
Última Aventura"
de Romy Pocztaruk:
uma viagem entre
as utopias e ruínas
na região amazôni-
ca. Revista Poiésis,
Niterói, v. 22 , n. 38 ,
p. 64 -81, jul./dez.
2021 . [https://doi.
org/10.22409/poie-
sis.v22i38.45679]
Este documento
é distribuído nos
termos da licença
Creative Commons
Atribuição-Não-
Comercial 4.0 Inter-
nacional [CC-BY-NC]
C 2021 Rafael Fontes
Gaspar

(Submetido: 31/8/2020 Acelto: $7 / 1 / 2021$ Publicado: 7/7/2021)
RESUMO Este artigo analisa a série de fotografias A última aventura [2011] da artista Romy Pocztaruk. A artista em suas fotografias revela as ruínas de Fordlândia demonstrando o fracasso do projeto utópico de Henry Ford e o cenário desolado das cidades que foram construídas ao redor da Rodovia Transamazônica. No ensaio $A$ nostalgia das ruínas, de Andreas Huyssen, podemos compreender que as ruínas da modernidade demonstram o declínio das promessas modernas, que falharam ou que não se concretizaram ainda.

PALAVRAS-CHAVE ruína nas artes visuais, ruína industrial nas artes visuais, Fordlândia, Romy Pocztaruk

ABSTRACT This article analyzes the series of photographs The Last Adventure [2011] by artist Romy Pocztaruk. In her photographs, the artist reveals the ruins of Fordlândia demonstrating the failure of Henry Ford's utopian project and the desolate scenery of the cities that were built around the Transamazon Highway. In the essay The nostalgia for the ruins of Andreas Huyssen we can understand that the ruins of modernity demonstrate the decline of modern promises, which have failed or have not yet come to fruition.

KEYWORDS ruin in the visual arts, industrial ruin in the visual arts, Fordlândia; Romy Pocztaruk

RESUMEN Este artículo analiza la serie de fotografías La última aventura [2011] del artista Romy Pocztaruk. En sus fotografías, la artista revela las ruinas de Fordlândia, demostrando el fracaso del proyecto utópico de Henry Ford y el paisaje desolado de las ciudades que se construyeron alrededor de la Carretera Trans-Amazónica. En el ensayo La nostalgia por las ruinas de Andreas Huyssen podemos entender que las ruinas de la modernidad demuestran el declive de las promesas modernas, que han fracasado o aún no se han concretado.

PALABRAS CLAVE ruina en las artes visuales, ruina industrial en las artes visuales, Fordlândia, Romy Pocztaruk

\footnotetext{
* Rafael Fontes Gaspar é Doutor em Artes Visuais pela Universidade Estadual de Santa Catarina. Email: rafaelfontesgaspar @gmail.com, ORCID: https://orcid.org/0000-0002-7938-7310
} 
Brasil é um construtor de ruínas. O Brasil constrói ruínas em dimensões continentais".

\section{Eliane Brum [2019, p. 119]}

Romy Pocztaruk [Porto Alegre, 1984] em A última aventura [2011] apresenta uma série de fotografias captadas em sua viagem pela Rodovia Transamazônica, que revelam o cenário de desolação e de ruínas de algumas cidades da região norte do Brasil. A artista percorreu de carro quase quatro mil quilômetros visitando, no estado do Pará, as cidades de Rurópolis, Brasil Novo, Altamira, Bandeiras e Fordlândia, a cidade de Henry Ford abandonada na selva amazônica. A série A última aventura de Romy Pocztaruk foi comissionada pelo programa Rumos Itaú Cultural e exposta na 31a Bienal Internacional de São Paulo de 2014, com o título: "Como [...] coisas que não existem". De acordo com Ana Maria Maia [2014, p.160-161], no catálogo desta bienal: "A viagem propunha a vivência de uma espécie de conquista do território e do imaginário que, apesar de tomados como símbolo de uma identidade nacionalista, permanecem inacessíveis e estigmatizados até hoje". Nas fotografias da artista, observa-se um cenário de desolação e despovoamento na região amazônica, que nos indica uma crítica aos projetos de desenvolvimento implantados na região norte do Brasil.
Romy Pocztaruk na série A última aventura percorre a estrada BR-230, também conhecida como Rodovia Transamazônica, que permanece inacabada desde sua inauguração em 1972. Construída durante o regime militar [1969-1974] do presidente Emílio Garrastazu Médici [1905-1985], fez parte do programa de "integração nacional" do governo, com o objetivo de ocupar as áreas pouco habitadas da região norte do país [MENEZES, 2007]. Mas, o que restou do projeto que garantia o desenvolvimento econômico da região encontra-se em ruínas, daquilo que ainda não se concretizou e ainda está por vir. Após 48 anos de sonhos e promessas, o polêmico projeto da Rodovia Transamazônica representaria um progresso ou um equívoco? Nas fotografias da série A última aventura de Romy Pocztaruk, contemplamos apenas o que restou da política desenvolvimentista do regime militar, entre a década de 1960 e 1970, naquela região.

Vale lembrar que o projeto faraônico da Rodovia Transamazônica foi desenvolvido durante o período que ficou conhecido como "milagre econômico". Neste contexto, o índice de desenvolvimento e crescimento econômico do país com a expansão do setor industrial, o aumento nas exportações agrícolas e o surgimento de novos empregos, geraram investimentos estrangeiros que permitiram a construção de rodovias, pontes e hidrelétricas, 
para ampliar o crescimento da economia. Assim, as regiões do Norte e do Centro-Oeste do país que são pouco habitadas foram estimuladas a receber investimentos com o intuito de se tornarem povoadas e economicamente desenvolvidas [MENEZES, 2007]. No entanto, a construção da Rodovia Transamazônica estimulada pela euforia e pelo ufanismo do "milagre econômico" foi interrompida, deixando para trás apenas as promessas e um cenário de desolação. Ana Maria Maia observa o projeto ambicioso da construção da Rodovia Transamazônica, que deixou para trás apenas rastros e desolação. A curadora de artes descreve: rastro de devastação e de ruínas, como nos revela a série A última aventura de Romy Pocztaruk, que documentou o cenário de desolação das cidades que foram construídas em função da estrada. Com a construção da Rodovia Transamazônica, veio a promessa de se conseguir uma terra pela primeira vez na vida, entretanto, os programas de governo entre a década de 1960 e 1970 promoveram apenas uma sangria sem limites na natureza [MENEZES, 2007]. A política desenvolvimentista da época estabeleceu modelos de cidades que seriam criadas, mas quase nada resistiu ao tempo. O que sobrou foi a lama, a poeira, o isolamento e os desafios que até hoje atormentam os viajantes da Rodovia Transamazônica.

A construção de seus 4 mil quilômetros - que iriam da Paraíba ao Acre, chegando à fronteira com o Peru - representava um empreendimento faraônico para a época, algo digno de um país em crescimento, "a última grande aventura do século", segundo a propaganda de Estado. Após alguns anos, as obras de diversos trechos da rodovia foram paralisadas e, com o passar do tempo, a Transamazônica converteu-se em um cenário de promessas não realizadas, longos vazios e esperas, ruínas do que nunca chegou a ser [MAIA, 2014, p. 160].

Nota-se que Romy Pocztaruk retoma no título do seu trabalho o slogan da propaganda do governo militar, que defendia com a construção da Rodovia Transamazônica "a última grande aventura do século". Assim, podemos imaginar a dimensão que o projeto faraônico da Transamazônica representava naquele período. Mas, o projeto utópico e ufanista da construção da Transamazônica deixou apenas um
Entre as cidades que não se desenvolveram após a construção da Transamazônica está Rurópolis, cidade que Romy Pocztaruk documenta em sua viagem pela estrada. A cidade de Rurópolis foi inaugurada com a presença de Médici, representando um local importante na história da Rodovia Transamazônica. A cidade seria um centro de referência para os outros munícipios na região da Amazônia [MENEZES, 2007]. Nas fotografias de Romy Pocztaruk, o espectador contempla o interior das casas dos moradores de Rurópolis, como mostra a Figura 1. 
Segundo Ana Maria Maia [2014, p.161]: "Apesar de esvaziados pela direção fotográfica, casas, parques e ruas apresentam uma dimensão humana em detalhes de sua ambiência e cultura material". Nessa fotografia observa-se um quadro pendurado na parede, de autoria desconhecida, que mostra a construção da estrada que prometia transformar economicamente a região amazônica. Este quadro na parede documentado pela artista expressa a transformação do território norte do Brasil, com as máquinas, os caminhões e a estrada que avançou pela região desmatando a floresta amazônica e deixando para trás os materiais remanescentes de um projeto faraônico e utópico.
A pintura no interior da sala, captada pelo olhar documental de Romy Pocztaruk, revela o contraste entre o homem e a natureza que a construção da Rodovia Transamazônica representa até hoje. Nos detalhes da casa, dos móveis e dos objetos dos moradores que são retirados de cena, a artista capta as imagens pela lente fotográfica expressando a identidade do local. Como mostra a Figura 2, observa-se o interior de um hotel desativado na cidade de Rurópolis, que hospedaria turistas do país e do mundo que visitariam a região norte do Brasil. Na fotografia vemos um painel de uma paisagem de seringueiras com o título de Altamira, cidade tida como marco zero da Rodovia

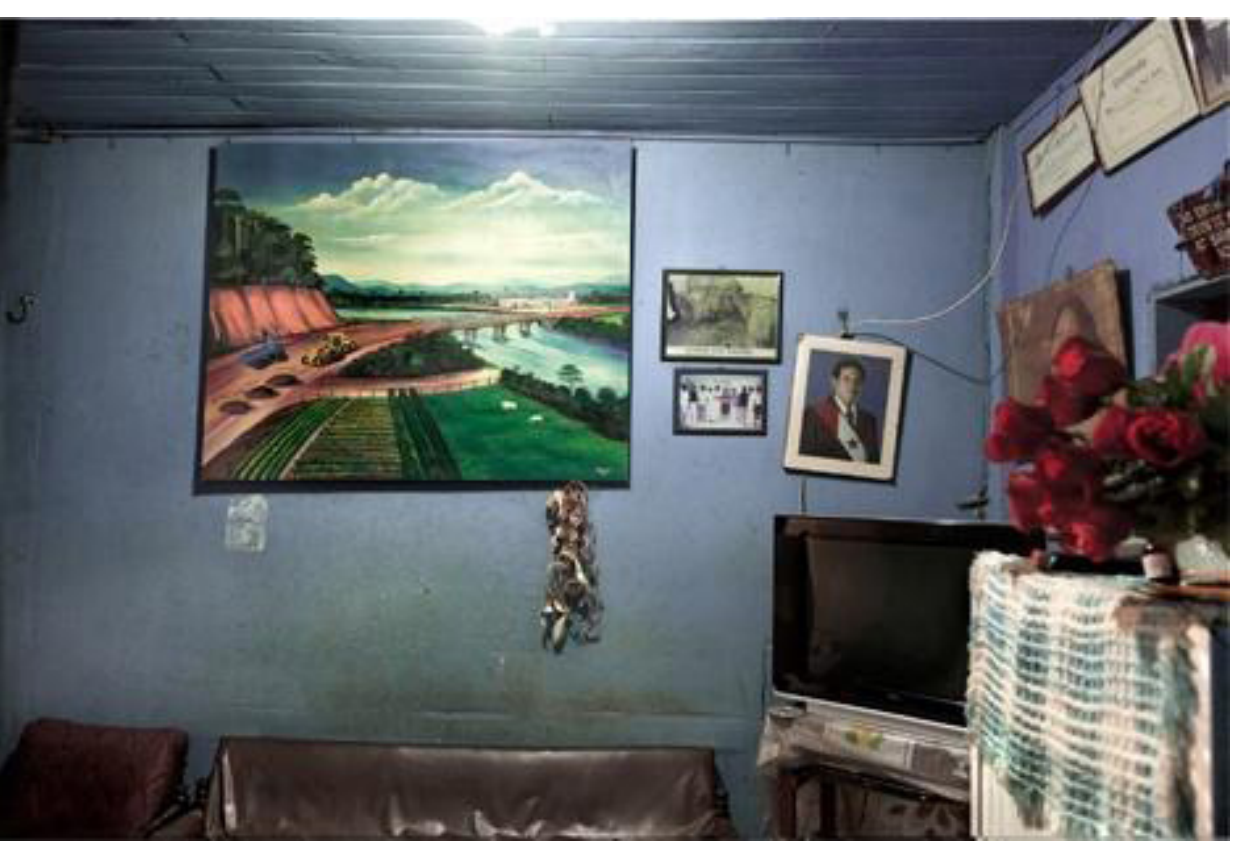

Transamazônica. Este hotel na cidade de Rurópolis representava a esperança do desenvolvimento econômico e social que a Transamazônica traria à região, mas o que se vê com as fotografias de Romy Pocztaruk são imagens de um cenário desolado de construções abandonadas.

Fig. 1 - Romy Pocztaruk. A última aventura, Rurópolis IV, 2011.

Fotografia, impressão jato de tinta sobre papel algodão

[Fonte: https://www.romypocz.com/work/a-ultima-aventura. Acessado em 10/072020] 


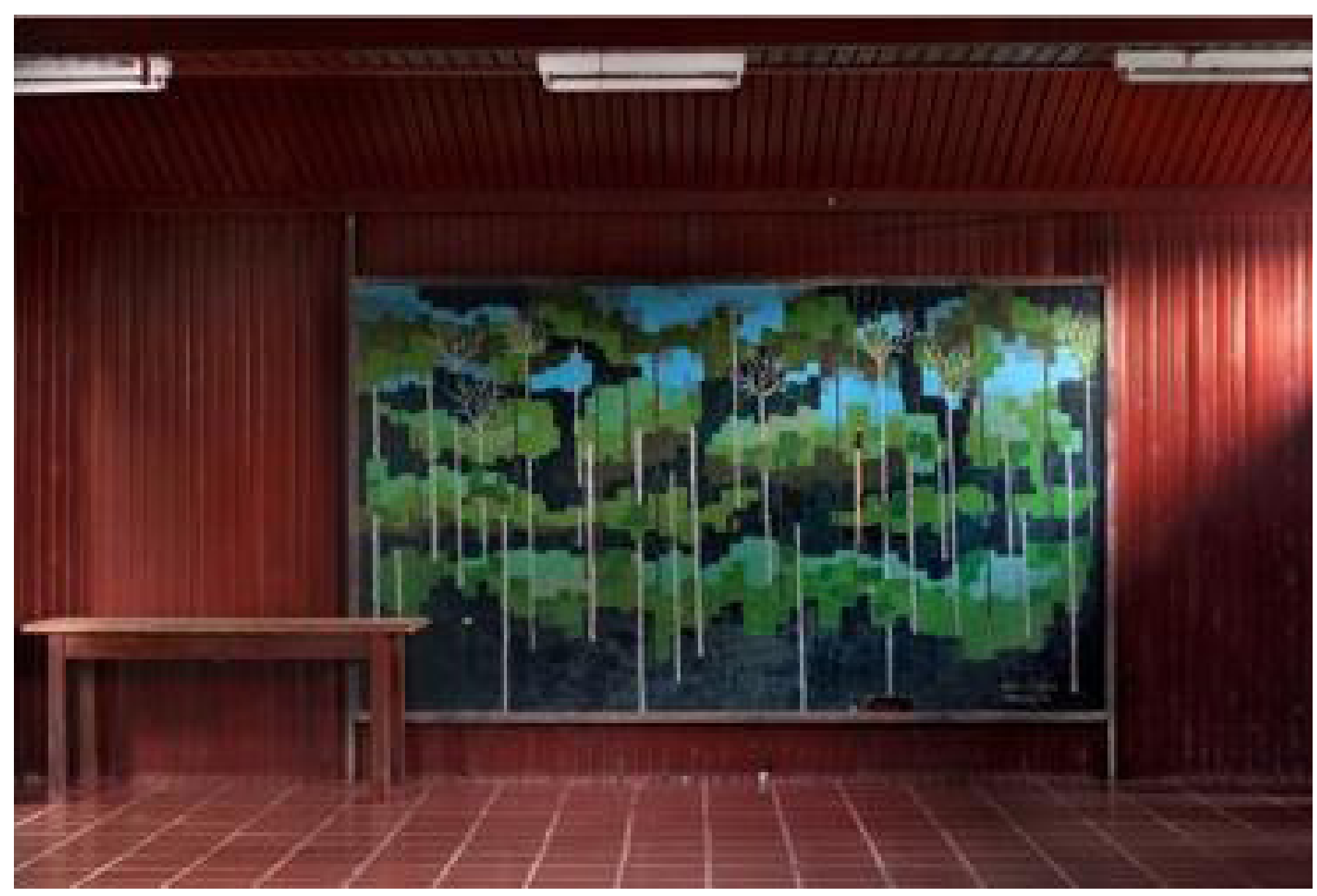

Fig. 2 - Romy Pocztaruk. A última aventura, Rurópolis II, 2011.

Fotografia, impressão jato de tinta sobre papel algodão

[Fonte: https://www.romypocz.com/work/a-ultima-aventura. Acessado em 10/7/2020] 
O cenário de desolação nas fotografias revela o fracasso do projeto faraônico da Rodovia Transamazônica. Assim, a estrada segue cheia de desafios como a vida de quem ainda acredita nela. Da viagem de Romy Pocztaruk pela região norte do Brasil, destacam-se também as ruínas de Fordlândia. No começo do século XXI, as ruínas de Fordlândia se tornam um destino turístico, despertando o interesse de muitos visitantes, historiadores, artistas, fotógrafos e cineastas. Os artistas e viajantes que visitam Fordlândia se deparam com o modelo de uma "cidade empresa" com o estilo norte-americano, que foi planejada para abrigar os funcionários da Companhia Ford Industrial do Brasil.

Romy Pocztaruk em A última aventura documenta a cidade de Fordlândia, localizada no estado do Pará, no munícipio de Aveiro, às margens do rio Tapajós. A construção da Company Townou "cidade empresa" - fundada por Henry Ford, em 1927, prometia mudar a história econômica e social da Amazônia. Mas, com as fotografias de Romy Pocztaruk podemos ver que restaram apenas as ruínas do ambicioso projeto da Companhia Ford Industrial do Brasil implantado na floresta amazônica. Ford inicia a construção de Fordlândia, com a intenção de abastecer a sua produção de pneus, mangueiras e demais produ- tos em sua indústria automobilística em Detroit, no distrito de Deaborn, para fugir do monopólio inglês da borracha, proveniente do látex extraído das seringueiras [Hevea brasiliensis] plantadas na Ásia. Como descrito por Cristovam Sena,

\begin{abstract}
Vivia-se a era do automóvel e da borracha, e o mundo precisava da matéria prima a qualquer preço. Durante o século XIX, praticamente toda borracha natural consumida no mundo era originária da Amazônia brasileira, levando o produto a competir com o café na formação do PIB brasileiro [SENA, 2008, p.91].
\end{abstract}

Assim, Ford decidiu ter a sua própria produção de borracha com a plantação das seringueiras cultivadas na floresta amazônica. No entanto, com a inexperiência na agricultura equatorial, no plantio de seringueiras, a produção de látex tornou-se insuficiente. Segundo Greg Grandin [2010], as seringueiras foram plantadas muito próximas entre si, ao contrário de como realmente são cultivadas, assim, tornaram-se uma presa fácil para as pragas e micro-organismos que dizimaram as plantações, contribuindo para o processo de decadência da cidade. Posteriormente, com o advento da borracha sintética produzida pelo petróleo, o projeto foi completamente extinto. Em 1945, com a desativação do projeto, a cidade foi tomada pelo mato e pelo abandono. 


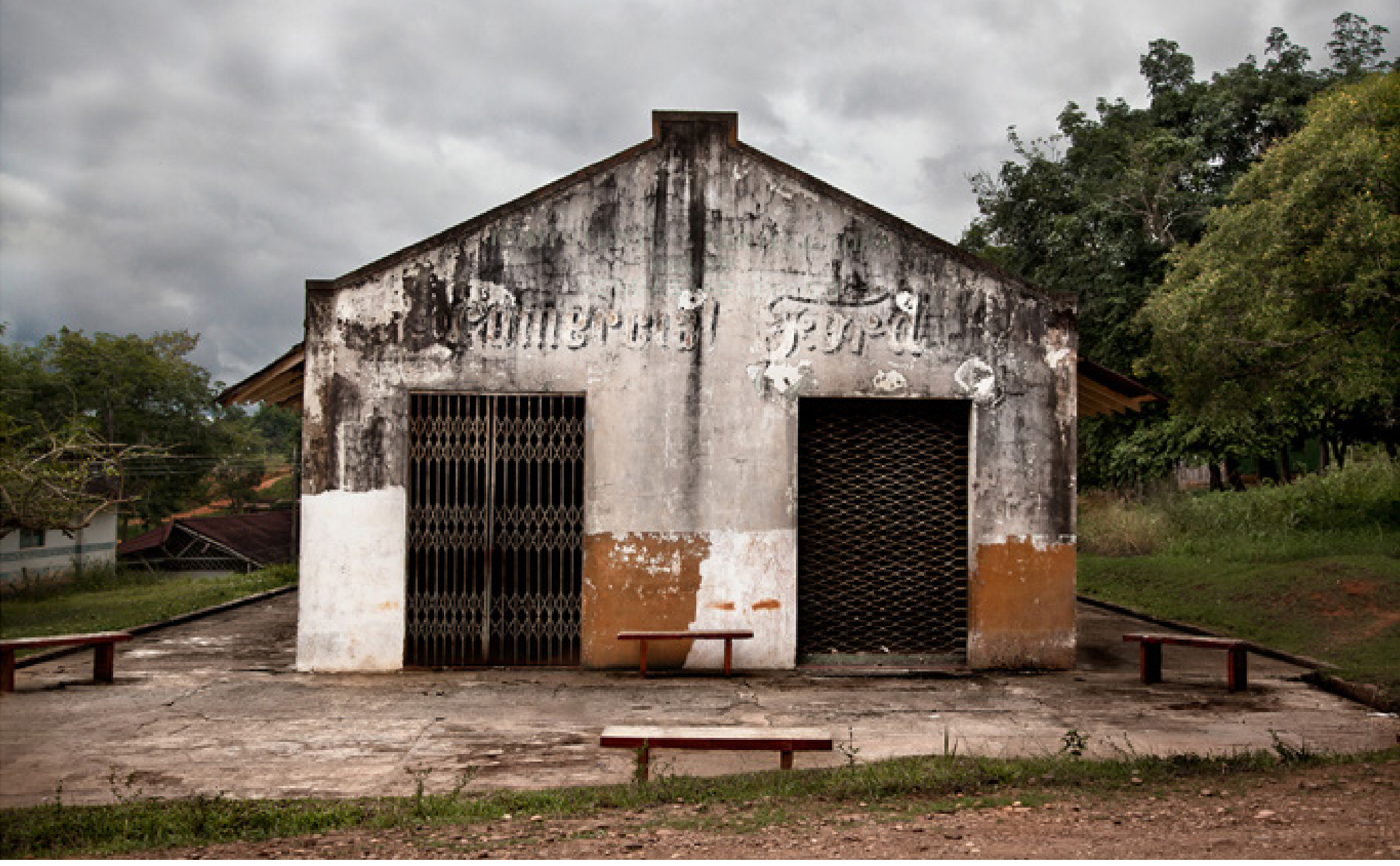

Fig. 3 - Romy Pocztaruk. A última aventura, 2011.

Fotografia, impressão jato de tinta sobre papel algodão.

[Fonte: https://romypocz.com/A-ultima-aventura. Acessado em 20/07/20] 
Nesse sentido, Romy Pocztaruk em A última aventura compõe uma série de fotografias de sua viagem à Fordlândia que, ao revelar o fracasso de Henry Ford com as ruínas da cidade, despertam nosso olhar para os destroços da paisagem contemporânea. As ruínas de Fordlândia compreendidas sob a lógica do capitalismo demonstram o declínio de cidades que sofreram o processo de desindustrialização. Neste caso, trata-se de uma Company Town, que se desenvolve em função do monopólio industrial sustentado em uma única produção ou extração de matéria-prima [GARNER, 1992]. De modo geral, quando a extração ou a fabricação de um produto entra em declínio, as indústrias são desativadas e declaram falência. Assim, os trabalhadores perdem o emprego e muitos deixam tudo para trás. Casas são abandonadas, escolas, lojas

e hospitais são fechados. Logo, surge um cenário em ruínas. Como mostra a Figura 3, o armazém abandonado com as grades revela o sonho falido de Henry Ford. Nota-se que na fotografia, a logomarca Comercial Ford vai desaparecendo com a tinta da fachada, que se encontra toda descascada. Vemos os efeitos provocados pela ação do tempo, que já pode ser percebida pela cidade.
Com isto, nos deparamos com o abandono visto no silêncio dos bancos solitários que denunciam o esquecimento e a degradação do local.

Na fotografia, o nome de Ford está desaparecendo, mas o sonho da sua indústria abandonada ainda permanece no meio da floresta amazônica. Olgária Matos [2009] analisa a queda da cidade de Henry Ford a partir da visão de Benjamin [2018], pelo projeto das Passagens, que nos indica as ruínas da modernidade originadas pela sociedade mercantil. As ruínas de Fordlândia nos revelam o modo como as construções modernas são facilmente descartadas pela lógica capitalista. Em Olgária Matos vamos encontrar o seguinte esclarecimento:

Se as ruínas são testemunhas que resistem ao poder destruidor do tempo, Fordlândia corresponde, antes, à lógica do Capital. Ao tratar do capitalismo triunfante na Paris do século XIX, Benjamin anotou que nos monumentos da burguesia se reconhecem ruínas antes de seu desmoronamento [MATOS, 2009, s/n].

Convém observar que Benjamin compreende no projeto das Passagens as ruínas como consequência da fragilidade dos "monumentos da burguesia", especialmente sob a luz da metrópole parisiense do século XIX. Igualmente, Matos segue a visão de Benjamin sobre as transformações da capital francesa, lançando o pensamento do filósofo para o fracasso da cidade de Ford implantada na floresta amazônica. Benjamin caracteriza pela visão de 
Balzac, mencionada no projeto das Passagens, o contraste entre os monumentos da burguesia em relação as ruínas da Antiguidade. Assim, ao citar o escritor francês, afirma:
Pocztaruk pela Transamazônica, os espaços e vazios urbanos se apresentam, a meu ver, como "os buracos" descritos por Robert Smithson quando analisa a entropia da paisagem urbana de sua cidade natal, ao dizer que:

As ruínas da lgreja e da Nobreza, as do Feudalismo, da ldade Média são sublimes e hoje enchem de admiração os vencedores, que ficam surpresos, boquiabertos; mas as da Burguesia serão um ignóbil detrito de cartonagem, de gessos, de coloridos [BALZAC apud BENJAMIN, 2018, p. 173]

\begin{abstract}
Passaic parece cheia de "buracos", comparada com a cidade de Nova York, que parece compacta e sólida, e esses buracos em certo sentido são os
\end{abstract} vazios monumentais que definem, sem tentar, os traços de memória de uma série de futuros abandonados [SMITH$\mathrm{SON}, \mathrm{p} .165]$

Por um lado, Romy Pocztaruk realiza uma jornada por uma estrada faraônica e inacabada que atravessa a imensa floresta amazônica. Por outro lado, Robert Smithson caminha pelo subúrbio de Passaic, após pegar um ônibus de New York, da cidade mais populosa e moderna dos Estados Unidos. A entropia da paisagem urbana de Passaic descrita por Robert Smithson em Um passeio pelos monumentos em Passaic, 1967 revela a estagnação de cidades industriais que encolheram. Com efeito, os monumentos modernos não deixam legado para a geração posterior. Em contraposição à ruína romântica, as ruínas da modernidade não simbolizam um passado glorioso como nos apresenta as construções colossais do Império Romano, mas denotam principalmente a falência dos projetos 
da era moderna. Nesse sentido, Robert Smithson descreve o que observou sobre o passado industrial de Passaic, ao dizer que:

Esse panorama zero parecia conter ruínas às avessas, isto é, todas as novas edificações que eventualmente ainda seriam construídas. Trata-se do oposto da "ruína romântica" porque as edificações não desmoronam em ruínas depois de serem construídas, mas se erguem em ruínas antes mesmo de serem construídas [SMITHSON, 2001, p. 165].

No trecho acima, a expressão usada por Robert Smithson, "ruínas às avessas", nos coloca uma questão perturbadora, pois, se lembramos de Roma pelas ruínas e pelos monumentos da Antiguidade, que simbolizam a grandeza do seu tempo, o que as ruínas e os monumentos da era moderna irão representar para as futuras gerações? Assim, à luz do pensamento de Andreas Huyssen [2014], podemos compreender que a viagem de Romy Pocztaruk pela Rodovia Transamazônica revela com as ruínas industriais de Fordlândia o fracasso do projeto utópico e ufanista de Henry Ford, abandonado na floresta amazônica. Para Andreas Huyssen [2014, p. 93], "temos saudade das ruínas da modernidade porque elas ainda parecem encerrar uma promessa que desapareceu da nossa era: a promessa de um futuro alternativo". Enquanto a nostalgia romântica pelas ruínas romanas representava a saudade por uma época gloriosa do passado, as ruínas industriais de Fordlândia simbolizam o fracasso da utopia de uma "cidade empresa" erguida na selva amazônica. Nesse sentido, analisa-se na série A última aventura de Romy Pocztaruk, o que podem revelar as ruínas e os resquícios remanescentes da construção da Rodovia Transamazônica e da cidade esquecida de Henry Ford, na floresta amazônica.

As fotografias de Romy Pocztaruk sobre as ruínas de Fordlândia estimulam o debate sobre o esquecimento e a "memória dos espaços de produção" [MENEGUELLO, 2013]. Salienta-se que a pesquisadora Cristina Meneguello desaprova a ideia de "patrimônio industrial" e sugere que este conceito seja pensado em termos de "memória do trabalho" ou "memória dos espaços de produção" [MENEGUELLO, 2013, p.251], com o intuito de abandonar a carga colecionista e degradada que foi adquirida pelo conceito de "patrimônio". A pesquisadora apresenta, de certa maneira, uma visão pessimista sobre a requalificação das ruínas industriais no Brasil, que nos ajuda a pensar sobre as ruínas de Fordlândia. Para Cristina Meneguello, as ruínas industriais no Brasil não são valorizadas em relação ao valor dado às antigas fábricas que se transformaram em centros culturais na Europa, ao afirmar que: 
Também estamos muito distantes de termos os equivalentes às rotas industriais existentes na Catalunha, Espanha, no Reino Unido, na Itália, nos Países Baixos,... ali, as rołas foram pensadas exałamente para abarcar diferentes tipologias ou formas de produção fabril, e associadas a museus de ciência e de técnica [MENEGUELLO, 2013, p.252]

Apesar da visão pessimista sobre a ideia de se constituir rotas turísticas no Brasil e centros culturais com as ruínas industriais, Meneguello [2013] menciona alguns exemplos de restauros conhecidos como a requalificação da antiga fábrica de tambores feita pela arquiteta Lina Bo Bardi, transformando-a em SESC Pompéia, na cidade de São Paulo - SP. Neste caso, verifica-se que as ruínas de Fordlândia nunca passaram por um processo de requalificação no sentido "nobre". Nas fotografias de Romy Pocztaruk, o patrimônio industrial de Ford aparece abandonado na selva. Tal como afirma Andreas Huyssen: "As ruínas do século XXI são detritos ou são velhice restaurada" [HUYSSEN, 2014, p.96]. Nesse sentido, as fotografias da artista documentam o desaparecimento da memória do espaço de produção construída pela Ford Motor Company na Amazônia. Como mostra a Figura 4, o espaço vazio de um armazém abandonado, ocupado por uma estante enferrujada, gera um desencanto com o estado de decadência.
Romy Pocztaruk torna visível, na imagem acima, os vestígios da era industrial, revelando a tensão entre a memória e o esquecimento do espaço de produção dos antigos trabalhadores de Fordlândia. $\bigcirc$ galpão industrial abandonado na selva, visto na imagem acima, expressa as consequências do processo de desindustrialização da cidade. Para Meneguello [2013], entretanto, algumas requalificações de antigas fábricas apagam, com o novo uso do local, a memória do trabalho acerca dos acidentes, das lutas e de toda rotina que envolve o trabalhador, incluindo o assédio às mulheres, que aconteciam nesses locais. Dessa maneira, para "preservar" a memória do trabalho por meio do processo de higienização das antigas fábricas, Meneguello [2013, p.253] sugere que seja dado um uso "nobre" para esses espaços e afirma: "Por isso, acho particularmente discutiveis os restauros que trazem usos entendidos como "nobres", ou seja, museus ou centros culturais". Assim, os restauros considerados "nobres" devem transformar a arquitetura arruinada em museus, ou, centros culturais, com o intuito de conservar as "memórias difíceis" do local. Como mostra a Figura 5, Romy Pocztaruk documenta uma sala abandonada, que talvez poderia ser utilizada dentro de um centro cul- 
tural, preservando a memória dos trabalhadores que construíram a cidade. Assim, a requalificação teria um uso "nobre" para os moradores e turistas que visitassem a região. Mas, constata-se nesta sala, que abriga a antiga fábrica de Ford, apenas um amontoado de papéis e pastas espalhadas, de recibos, notas e documentos que ficaram para trás.
Fig. 4 - Romy Pocztaruk. A última aventura, Fordlândia IX, 2011. Fotografia, impressão jato de tinta sobre papel algodão, $110 \times 165 \mathrm{~cm}$ [Fonte: https://www.zippergaleria.com.br/pt/artistas/romy-pocztaruk. Acessado em 20/07/2020]

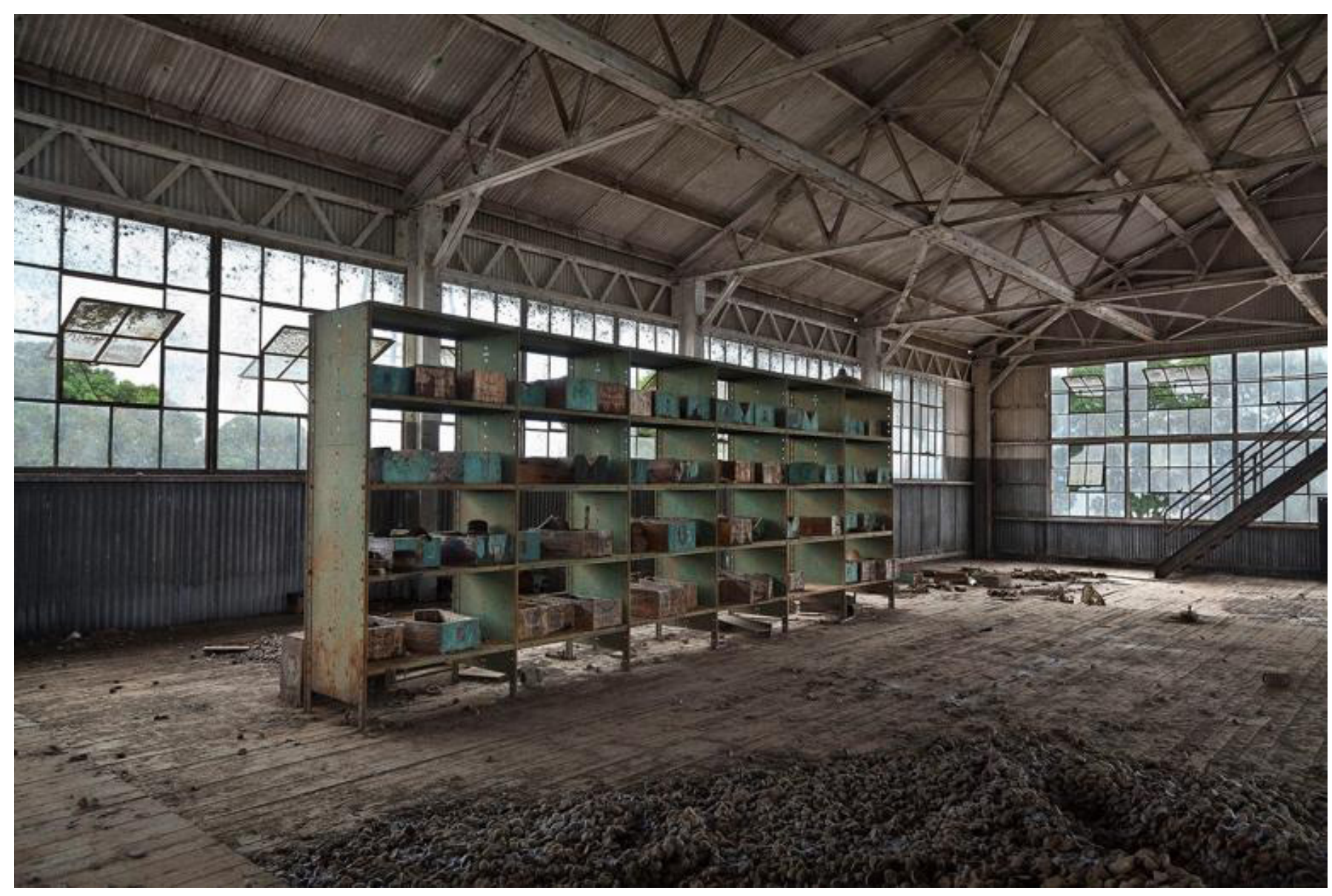




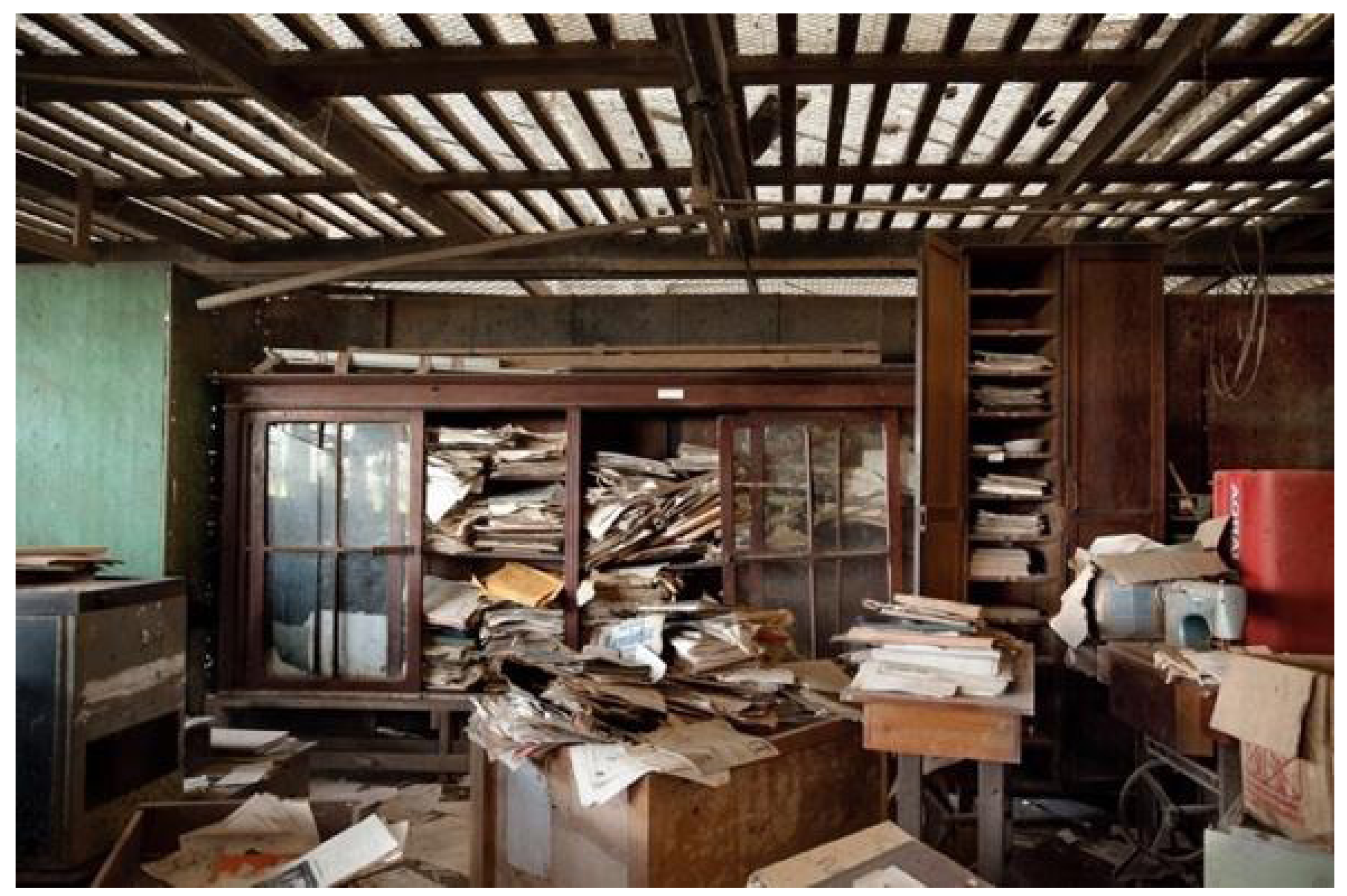

Fig. 5 - Romy Pocztaruk. A última aventura, Fordlândia, 2011. Fotografia, impressão sobre papel algodão

[Fonte: https://www.zippergaleria.com.br/pt/artistas/romy-pocztaruk. Acessado em 20/7/2020] 
As fotografias de Romy Pocztaruk sobre as ruínas de Fordlândia denunciam o descaso com a memória do local de produção. Não podemos esquecer que os moradores convivem com essas ruínas, que não são detalhes isolados no ambiente urbano. Contudo, como foi visto, as releituras e os novos usos que são dados às antigas fábricas podem resultar no apagamento de certas memórias. Conforme Meneguello [2013], a requalificação do espaço apaga a memória, higieniza e ordena o local. As fábricas são limpas e iluminadas, o antigo espaço que abrigava o estampido das máquinas é substituído por uma música ambiente que seja agradável aos ouvidos. Dessa maneira, a pesquisadora defende a incorporação e o reconhecimento das ruínas industriais, que são descartadas ou recicladas, que apagam a "memória do espaço de produção". Nesse sentido, Meneguello [2013] se opõe à visão geral de urbanistas e arquitetos que enxergam nas ruínas apenas uma deficiência constante no tecido urbano das cidades contemporâneas. Dessa forma, a pesquisadora defende o caráter "pedagógico" das ruínas industriais, ao expressar que:

Para mais além, arrisco que as ruínas industriais têm a mesma capacidade de nos ensinar sobre o passado que têm as ruínas da Antiguidade. Elas nos falam da obsolescência das nossas tecnologias e formas de produção, falam dos recentes processos de desindustrialização e de informatização do trabalho e do emprego, falam em como a tecnologia se transforma predando e incorporando tecnologias anteriores [MENEGUELLO, 2013, p.253].

Em conformidade com Meneguello [2013], as ruínas industriais de Fordlândia apresentadas pela documentação de Romy Pocztaruk têm muito a nos ensinar. Essas ruínas servem como lembretes dos danos causados pela arrogância de um projeto industrial que ignorou o meio ambiente e a população da região norte do Brasil, deixando para trás apenas um rastro de devastação e abandono. Apesar do conflito entre o sonho de Ford e o meio ambiente da floresta amazônica, o local de produção em ruínas ainda abriga a memória de muitos trabalhadores que passaram pela região e que ainda permanecem na cidade. Por isto, Meneguello [2013] se opõe ao uso utilitarista dado aos locais de produção, na medida em que esses espaços nos fornecem o conhecimento sobre as transformações da tecnologia e do trabalho, que eles possuem uma memória que nos ensina sobre o seu tempo, como as ruínas do mundo antigo nos ensinam sobre o passado. Menguello utiliza-se da seguinte argumentação: 
Contrastando com a ideia de que todo espaço possui uso e função, estas ruínas industriais funcionariam como um lembrete, um monumento aos nossos excessos e desperdícios. Visualizá-las nos permitiria intuir que formas de produção, saberes e ofícios foram extintos. A desordem que elas propõem nos tiraria de nosso ilusório conforto [MENEGUELLO, 2013, p.254]

As ruínas industriais de Fordlândia documentadas por Romy Pocztaruk nos perturba quando analisamos as consequências da ambição de Ford, da construção da sua cidade utópica na floresta amazônica. Enquanto alguns defendiam no passado que o magnata industrial libertaria a região amazônica do atrasado, conforme demonstra o historiador Greg Grandin [2010], o que podemos constatar do seu legado na Amazônia são apenas ruínas e a esperança daqueles que lá vivem. Dessa maneira, seria difícil conservar a memória da antiga fábrica da Fordlândia, estando localizada em uma região tão isolada do centro econômico do Brasil. Para Meneguello [2013], as antigas fábricas abandonadas estão localizadas em áreas que são, de modo geral, muito lucrativas e que estão sob o domínio da especulação imobiliária, que é quem domina e dá as cartas na dinâmica urbana. Nesse contexto, dificilmente se encontra no país o uso e utilização de antigas fábricas a favor do público e do coletivo. Sobre a requalificação das antigas fábricas no Brasil, conforme Meneguello, em sua maioria o que se encontram são ruínas e abandono. Ao descrever o que encontrou viajando pelas antigas fábricas no estado de São Paulo, a pesquisadora afirma:

Recentemente, realizei um levantamento para o interior de São Paulo do que poderia ser uma suposta "rota industrial", mas acabei batizando-a de "rota de ruínas", pois todos os exemplares estavam em estado de abandono e esfacelamento [MENEGUELLO, 2013, p.252].

Se, para o estado de São Paulo que concentra a economia do país, as antigas fábricas estão em ruínas, o que deveríamos imaginar sobre as ruínas de uma antiga fábrica construída no começo do século XX na selva amazônica? Sabe-se que, até o momento não houve tombamento ou requalificação das ruínas industriais e do projeto urbanístico de Fordlândia. Nas imagens de Romy Pocztaruk, as ruínas e a vida dos moradores convivem lado a lado, entre a tristeza e a esperança, na documentação dos detalhes que o seu olhar fotográfico humaniza. Assim, em A última aventura, conhecemos a história da Transamazônica, dos vilarejos e de Fordlândia, por meio de ruínas e da vida que abrigam esses lugares; não nos deixa 
uma resposta, é um devir que ainda espera. No entanto, a meu ver, mesmo que a cidade se desenvolva em seu aspecto econômico e social no futuro, as ruínas industriais, ou seja, o local de produção que abriga a memória dos antigos trabalhadores, já não estará mais de pé, devido à ação do tempo, da natureza em sua volta e do descaso público com o patrimônio industrial de Ford deixado na floresta amazônica.

Desse jeito, o que resta sobre as ruínas de Fordlândia, talvez seja o "caráter pedagógico", que Cristina Meneguello [2013] defende, pois, a análise das ruínas industriais de Fordlândia documentadas em A última aventura permite compreender o que as ruínas da modernidade no Brasil têm a nos ensinar, principalmente, sobre a arrogância de Henry Ford, dos homens e das mulheres que foram enviados, muitos vindos da Península Superior de Michigan, como engenheiros, operadores de serra e lenhadores, que subestimaram o lado selvagem da natureza inexplorada da Amazônia, deixando para trás apenas um rastro de decadência e de falhas. Neste contexto, as ruínas de Forldândia e da Rodovia Transamazônica na série A última aventura de Romy Pocztaruk expressam a decadência e a destruição que pode ser encontrada no tecido urbano em diversas metrópoles. No entanto, essas ruínas revelam os rastros de uma destruição ambiental sem precedentes na história do Brasil, que se inicia com a edificação de Fordlândia em 1928 e com a construção da Rodovia Transamazônica em 1972.

Assim sendo, a obra A última aventura de Romy Pocztaruk apresenta as ruínas da modernidade e as utopias fracassadas da região norte do Brasil, que abriga, especialmente, a maior floresta tropical do mundo, a Amazônia. Gostaria que esse estudo e suas fotografias pudessem ser compreendidos também como mais uma denúncia sobre o esquecimento e o abandono das construções e dos monumentos na região norte do Brasil, que são vítimas da displicência, do desprezo e do descaso, público, ou, privado. 
BENJAMIN, Walter. Passagens. Belo Horizonte: Editora UFMG; São Paulo: Imprensa Oficial do Estado de São Paulo, 2018.

BRUM, Eliane. Brasil, construtor de ruínas - Um olhar sobre o país, de Lula a Bolsonaro. Porto Alegre: Arquipélago Editorial, 2019.

GARNER, John S. The Company Town: Architecture and Society in the Early Industrial Age. New York: Oxford University Press, 1992

GRANDIN, Greg. Fordlândia: ascensão e queda da cidade esquecida de Henry Ford na selva. Tradução de Nivaldo Montingelli Júnior. Rio de Janeiro: Rocco, 2010

HUYSSEN, Andreas. Culturas do passado-presente: modernismos, artes visuais, políticas da memória. Trad. Vera Ribeiro. Rio de Janeiro: Contraponto, 2014.

MAIA, Ana Maria. Aúltima aventura 2011 Romy Pocztaruk. Guia 31a Bienal de São Paulo: como [...] coisas que não existem] / Organizado por Nuria Enguita Mayo e Erick Beltrán. - São Paulo: Fundação Bienal de São Paulo, 2014.

MATOS, Olgária Chain Féres. Fordlândia: desindustrialização e crítica do presente. Carta Maior [S.l: s.n.], 2009

MENEGUELLO, Cristina. Espaços e vazios urbanos. [In] FORTUNA, Carlos; LEITE, Rogerio Proença. [org.] Plural de Cidade: Novos léxicos urbanos. Coimbra: CES, 2009. 
MENEGUELLO, Cristina. As Ruínas do Futuro e o Novo Patrimônio Industrial: Entrevista com Cristina Meneguello. [Entrevista concedida a] Anaxsuell Fernando da Silva e Wagner do Nascimento Rodrigues. CONTEXTO [MOSSORÓ], v. 4, p. 249-255, 2013.

MENEZES, Fernando Dominience. Enunciados sobre o futuro: ditadura militar, Transamazônica e a construção do "Brasil grande". Dissertação de Mestrado em História - História Social, Programa de Pós-Graduação da Universidade de Brasília, UNB. Brasília - DF, 2007.

SANTOS, Cecilia Rodrigues dos; ZEIN, Ruth Verde. Rápidas considerações sobre a preservação das ruínas da modernidade. Arquitextos, São Paulo, ano 12, n. 135.00, Vitruvius, jul. 2011 <http://www.vitruvius.com.br/ revistas/read/arquitextos/12.135/3997>.

SENA, Cristovam, "Fordlândia: breve relato sobre a presença americana na Amazônia". In Cadernos de histórias da ciência - Instituto Butantan, São Paulo, 2008, V. 4, N², pp. 89-107.

SMITHSON, Robert.'Um Passeio pelos Monumentos de Passaic, Nova Jérsei'. [Trad. Pedro Sussekind]. Jornal O Nó Gordio n. 1. Rio de Janeiro, 2001. 